\title{
O Sindicato dos Estivadores do Porto de Santos e o processo de modernização portuária*
}

\author{
Maria Aparecida Ferreira de Aquiar** \\ Luciano Antonio Prates Junqueira*** \\ Antonio Carlos de Moura Freddo****
}

S UMÁRIO: 1. Introdução; 2. Sindicato dos Estivadores do Porto de Santos; 3. Lutas internas, natureza do trabalho da estiva e controle do trabalho pelo SES; 4. Características do trabalho da estiva; 5 . O controle do mercado de trabalho pelo sindicato; 6. Distribuição do trabalho no passado e no presente: sindicato versus Ogmo; 7. Considerações finais.

Summary: 1. Introduction; 2. The Stevedores' Union of the Port of Santos; 3. Internal struggles, nature of the stevedores' work, and labor control by the Sups; 4. Characteristics of the stevedores' work; 5. Labor market control by the union; 6 . Assignment of jobs in the past and in the present: union versus Ogmo; 7. Final remarks.

Palavras-chave: modernização portuária; sindicato de estivadores; porto de Santos; Ogmo; globalização.

KEY WORD S: port modernization; stevedores' union; port of Santos; Ogmo; globalization.

\footnotetext{
* Artigo recebido em dez. 2005 e aceito em ago. 2006.

** Doutora em psicologia social e do trabalho pela USP e professora-assistente doutora do Programa em Gestão de Negócios da Universidade Católica de Santos (Unisantos). Endereço: Rua Carvalho de Mendonça, 144 - CEP 11070-906, Santos, SP, Brasil. E-mail: maf.aguiar@ uol.com.br.

*** Sociólogo, doutor em administração da saúde; professor titular da FEA/PUC-São Paulo. Coordenador do Programa de Estudos Pós-Graduados em Administração da PUC-São Paulo. Assistente doutor do Programa de Gestão de Negócios da Unisantos. Endereço: Rua Ministro Godoy, 969, 4ํadar — CEP 05015-901, São Paulo, SP, Brasil. E-mail: junq@pucsp.br.

$* * * *$ Doutor em sociologia pela USP e mestre em administração pela PUC-São Paulo. Professorassistente doutor do Programa em Gestão de Negócios da Unisantos. Endereço: Rua Carvalho de Mendonça, 144 — CEP 11070-906, Santos, SP, Brasil. E-mail acfreddo@uol.com.br.
} 
Este artigo é uma reflexão acerca do papel do Sindicato dos Estivadores da cidade de Santos no processo de modernização do porto. Aborda questões como a importância do porto no passado e no presente, a história do sindicato no decorrer do século XX, suas características, suas propostas e seu posicionamento em face da modernização portuária. Analisa a relação entre o processo de modernização do porto de Santos e o Sindicato de Estivadores, no contexto de um mundo globalizado, não só enfocando seu passado, mas, a partir dele, tentando compreender seu papel histórico na vida passada e presente do trabalhador portuário e na própria história do porto e da evolução socioeconômica da cidade de Santos. Este artigo é resultado de aproximação preliminar de pesquisas em desenvolvimento, cuja temática é a modernização do porto de Santos enfocando as transformações nas instituições e no trabalho ocorridas no processo.

\section{The Santos Stevedores' Union and the port modernization process}

This article reflects on role played by the Santos Stevedores' Union in the process of modernization of the Port of Santos. It discusses some important issues, such as the former and current importance of the union's history during the 20th century, its characteristics, proposals and position concerning port modernization. It analyzes the relationship between the modernization process of the Port of Santos and the Stevedores' Union in the globalized world, not only focusing on the past but also, from this perspective, trying to understand its historical role in the past and present standard of living of the port workers, in the history of the port itself and in the history of the socioeconomic development of the city of Santos. This article is a preliminary result of surveys still in progress focusing on the modernization of the Port of Santos, especially the institutional and labor changes that occurred in this process.

\section{Introdução}

A modernização dos portos brasileiros, especialmente a do porto de Santos, se deu como resposta à demanda de inserção do país no processo de globalização mundial, em uma economia globalizada. Entender a globalização como um processo multidimensional significa entendê-lo como vivência cotidiana da ação sem fronteiras que integra diferentes dimensões: econômica, da informação, tecnológica, ecológica e aquela dos conflitos transculturais e da própria sociedade civil (Beck, 1999). Ela desorganiza a ordem vigente e coloca novas demandas, transformando o cotidiano das nações, das organizações e das pessoas. Na globalização, como acentua Beck (1999), dinheiro, tecnolo- 
gia, mercadorias, informações, bem como pessoas, ultrapassam as fronteiras como se elas não existissem.

A dimensão econômica traz, entre outras características, a abertura de mercados, volatilidade de recursos financeiros, transferências de negócios de uma região do mundo para outra sem nenhum impedimento legal, desorganizando economias locais e provocando um processo competitivo entre organizações e países num nível nunca imaginado. As suas conseqüências são contraditórias, já que ao abrir os mercados nacionais, abrem-se possibilidades para um intercâmbio de negócios mais amplo, enfatizando a questão da competência e da competitividade de cada organização e de cada país. Ao mesmo tempo, possibilita uma liberdade sem controle ao mundo econômico, capaz de levar à destruição de estabilidades econômicas nacionais, gerando crises econômicas, sociais e políticas, como: recessão econômica; desemprego; e desequilíbrio da balança comercial, com o agravamento do processo de exclusão social.

A dimensão técnica, por sua vez, é marcada pela rapidez do desenvolvimento tecnológico, atingindo diferentes áreas e transformando-as. A tecnologia da informação, como acentua Beck (1999), é o marco mais radical de mudança tecnológica, tendo sido o que provocou uma profunda revolução no cenário do mundo, na esfera social, econômica, industrial e política, bem como na vida das pessoas. Ainda na dimensão técnica surge a robótica, que permite a rapidez, qualidade e exatidão, trazendo contribuições importantes aos vários campos, entre eles o setor portuário.

Em relação ao trabalho, elas são responsáveis por mudanças drásticas que vêm ocorrendo na estrutura e nas características do porto, o que demanda um novo trabalhador, do qual são exigidas novas qualificações, que envolvem diferentes conhecimentos, habilidades, características psicológicas, socioculturais e físicas, muitas vezes, antagônicas àquelas até então demandadas. Apesar da drástica redução de postos de trabalho tradicionais e da implantação de novas tecnologias, tanto a robotização quanto a informatização criaram novos postos de trabalho. Rifkin (2004), ao analisar as rápidas mudanças tecnológicas e seu impacto nos empregos, fala no surgimento de uma nova era, que trará novos bens e serviços e conseqüentemente novos empregos elitistas e restritos em número, que exigirão novas habilidades profissionais especialmente na arena mais sofisticada do conhecimento: enfermeiros e técnicos em laboratórios são substituídos, no setor de diagnóstico, por tecnologias sofisticadas.

É nesse contexto que se pretende entender as mudanças que vêm ocorrendo no porto de Santos. Primeiramente será mostrado o seu processo de formação, que teve início em 1532, quando começaram as atividades portuá- 
rias no estuário de Santos. Em 1888 foi concedida à iniciativa privada a exploração do porto de Santos. Com isso, surgiu o monopólio privado, que durou 92 anos, com término em 1980, quando foi criada a Codesp, órgão estatal que passou a ter o monopólio das operações do porto de Santos, caracterizando então o monopólio púbico.

Em 1993, esse monopólio foi revogado com a Lei de Modernização dos Portos (Lei no 8.630). A partir daí, profundas mudanças ocorreram na estrutura do porto organizado, como também na sua dinâmica. Desapareceu o monopólio público no porto de Santos e surgiu o Conselho de Autoridade Portuário (CAP), constituído por representantes do governo federal, oriundos do Ministério dos Transportes; por representantes dos municípios de Santos, Guarujá e Cubatão; dos operadores; dos trabalhadores portuários e do governo do estado de São Paulo. A função do CAP é legislativa. A administrativa passou a ser exercida pela Codesp (Companhia Docas de São Paulo), anteriormente responsável pelas operações portuárias.

Foi criado também o Órgão Gestor de Mão-de-obra (Ogmo), eliminando o controle de mão-de-obra avulsa pelos sindicatos dos trabalhadores portuários. Com o desaparecimento do monopólio público das operações portuárias entraram em funcionamento as operadoras com terminais próprios e operadores eventuais, características fundamentais de um porto privatizado.

Essas instituições - CAP, operadores, Ogmo e Codesp - como autoridades administrativas portuárias constituíram o processo de modernização portuária com o porto organizado. Surgiram novos atores sociais e novas relações institucionais, dando ao porto uma nova dinâmica.

A relação capital-trabalho foi reposicionada com o surgimento do Ogmo como gestor da mão-de-obra avulsa, redimensionando as funções específicas dos sindicatos dos trabalhadores da estiva, que vinham até então exercendo funções sindicais de gestor de mão-de-obra.

Este artigo pretende discutir, inicialmente, o novo papel do Sindicato dos Estivadores de Santos no contexto da modernização portuária. Em seguida, como o sindicato perdeu o controle do trabalho avulso no porto e o surgimento de um novo porto organizado.

\section{Sindicato dos Estivadores do Porto de Santos}

O Sindicato dos Estivadores do Porto de Santos sofreu grande influência estrangeira na sua constituição e trajetória de lutas e reivindicações. Portugueses e espanhóis formavam a estiva em Santos, com a marcada liderança dos espanhóis (Maram, 1979). Dos 39.802 estrangeiros residentes em San- 
tos, pelo censo de 1913, 8.343 (33\%) eram espanhóis que mantinham a liderança dos trabalhadores portuários. Segundo o autor, na greve dos estivadores de 1889, foi necessário chamar os cônsules de Portugal e da Espanha para acalmar os grevistas.

Em 1920 (Maram, 1979), 35,6\% da força de trabalho que se concentravam na Cia. das Docas era estrangeira, e defendiam o anarquismo como meio indispensável para a emancipação da classe operária. A influência estrangeira no porto de Santos foi sempre objeto de grande preocupação do governo brasileiro, que no decorrer da Primeira República usou a deportação como forma de reprimir as lutas dos trabalhadores no porto. Essa política foi mantida no Estado Novo, por Vargas - os estrangeiros eram deportados e os brasileiros enviados para a ilha dos Porcos (Tavares, 2001). Ainda no governo Vargas o novo Regulamento do Exercício da Profissão da Estiva e da Desestiva do Porto de Santos (art. 1ํㅡㄴㅜㅡ, de 27 de junho de 1946) adotou as seguintes medidas:

1) só poderão ser admitidos na estiva e nas docas, os trabalhadores brasileiros ou naturalizados: apenas em caráter excepcional poderão ser matriculados estrangeiros, sempre tendo em vista o tempo de domicílio e o de serviços já prestados;

2) as Delegacias de Trabalho Marítimo (DTM) ficam autorizadas a rever as matrículas já efetuadas de estivadores estrangeiros.

Em 1905 (Sarti, 1988), foi registrado um movimento grevista com proporções surpreendentes, pois contou com a adesão do proletariado santista, dos gráficos de São Paulo, e de um sindicato estivador do Rio de Janeiro. A greve foi realizada em resposta à negativa do setor da estiva de fornecer três turnos de serviço. A Internacional União Operária, de orientação anarcossocialista, coordenou a greve. A Internacional União Operária foi fundada em 1904 e teve grande adesão por parte dos operários de Santos tendo, em poucos meses, conseguido a adesão de um número de sócios superior a 10 mil.

A greve, coordenada pelo sindicato, durou 27 dias e foi violenta, com forte repressão por parte do governo, que enviou tropas ao porto de Santos para reprimir os grevistas. Foram efetuadas centenas de prisões e muitas deportações.

Em 1908, estoura nova greve dos operários da Cia. das Docas, com reivindicação de jornada de trabalho de oito horas e aumento salarial. A repressão, novamente, tomou a forma de uma guerra, com a participação de tropas do Exército e navios de guerra. É interessante ressaltar que o movimento grevista só foi debelado com a intervenção do Estado no papel de mediador. 
Em 1912 (Sarti, 1988), inúmeros protestos dos operários foram realizados contra a inflação e o alto custo de vida. Os trabalhadores das Docas pararam novamente por não terem recebido aumento salarial. A violência repressiva do governo voltou a se manifestar, com mais prisões e deportações de trabalhadores estrangeiros para reprimir o movimento. É desnecessário dizer que as reivindicações dos trabalhadores não foram atendidas.

Retomando a análise de Maran (1979), em 1919 o movimento operário recuperou sua dinâmica, após um movimento grevista que, mais uma vez, foi reprimido com grande violência pela polícia. Mas foi naquele ano que os operários conseguiram obter sua jornada de oito horas.

Ainda em 1919, Maram (1979) menciona um novo movimento com nova paralisação, cujo objetivo era aumento salarial e outros benefícios relativos às condições de trabalho. A greve durou dois meses e foi derrotada, tendo a Cia. Docas de Santos substituído seus 2.100 trabalhadores por outros, que não participaram da greve. Também em 1919 foi fundada a Sociedade dos Estivadores de Santos (SES), tendo como eixo ideológico, o anarcossindicalismo. É importante notar que a ação do movimento dos trabalhadores portuários estava comprometida com questões do cotidiano do estivador, como salários, jornada e condições de trabalho, seguindo a ideologia e as estratégias de luta inspiradas no movimento anarquista.

A partir de 1922, houve uma mudança radical na orientação ideológica da Sociedade dos Estivadores de Santos, que abandona o anarcossindicalismo e assume o comunismo como ideologia oficial. Isso só foi possível com a fundação do Partido Comunista e de seu reconhecimento oficial no mesmo ano.

Foi nesse momento histórico que a cidade de Santos iniciou sua trajetória revolucionária comunista, sob a orientação do PCB, sufocando sua identidade anarcossindicalista e, com ela, o seu cognome de Barcelona brasileira. No decorrer dos anos 1930 até 1951, a cidade de Santos ressurgiu como a Moscouzinha, como a cidade de Prestes. O porto de Santos, por sua vez, passou a ser conhecido como porto vermelho (Tavares, 2001; Sarti, 1981).

Em 1945, o PCB conseguiu eleger deputado federal, senador e vereadores, por meio de votações expressivas na cidade de Santos. Tavares (2001) ressalta que o período de 1930 a 1951 foi revolucionário, marcado pela ação comunista no SES. Todavia, o PCB não mantinha no SES uma hegemonia de pensamento, como indica um relatório policial citado pelo autor, referente à greve de 1933, quando foram identificadas sete correntes de cunho "socialista", assim descritas: comunistas stalinistas, comunistas trotskistas, comunistas prestistas, miguelismo, outubrismo, rabelismo e ditatoriais albertistas.

O enterro do anarcossindicalismo não foi, entretanto, pacífico. Lutas ideológicas, perseguições e violência caracterizaram, nesse período, a vida in- 
terna da Sociedade dos Estivadores de Santos. Agregada à violência interna surgiu a intervenção policial.

Em 1926 a Sociedade dos Estivadores foi fechada por ação policial. Os trabalhadores fizeram várias tentativas de reabertura, e sua reorganização tomou forma de luta aberta, violenta, especialmente em 1929 (Sarti, 1981; Tavares, 2001).

Somente em dezembro de 1930, com a interferência de um membro da força pública do estado de São Paulo, Miguel Costa, então secretário de Segurança Pública do governo da revolução de São Paulo, já em plena luta violenta, a Sociedade dos Estivadores de Santos teve sua sobrevivência assegurada como associação da categoria, afastando as ameaças de fechamento.

Nesse período foram assassinados o ensacador Deoclecio e o presidente do SES, Octávio Thomaz (Tavares, 2001).

\section{Lutas internas, natureza do trabalho da estiva e controle do trabalho pelo SES}

Tavares (2001), ao analisar as lutas internas no Sindicato dos Estivadores do Porto de Santos (SES), ressalta que elas nem sempre foram provocadas pela ideologia política, mas pelo direito ao trabalho. As características do trabalho da estiva e a forma pela qual o trabalho era distribuído, sem regras objetivas, eram focos de conflitos permanentes entre os trabalhadores que, muitas vezes, recorriam à força policial para garantir a ordem, o que para eles significava o direito ao trabalho. $\mathrm{O}$ fato dos trabalhadores andarem armados agravava o problema de trabalho na estiva, como ressalta Tavares (2001). Os grupos étnicos, religiosos e políticos, na análise do autor, se fechavam, dificultando a união dos trabalhadores em torno de uma ideologia política comum, acirrando ainda mais os conflitos internos.

Um panfleto, editado possivelmente em 1935, de autoria de Agapito de Souza, ex-combatente e candidato a presidente do SES, resultado de uma negociação com o PCB e Manoel Costa, exemplifica esta questão ("Digníssimos companheiros do Sindicato dos Estivadores de Santos", folheto, 1935. Pront. 2.594 - Centro Estivadores de Santos. Deopps/SP, Daesp, apud Tavares, 2001: 32). Souza assim se pronunciou:

Já procurando derrubar de vez os muros da intriga insidiosa que dividiu a classe, enfraquecendo e, numa palavra, tornando-a quase desaparelhada e impotente para empenhar-se, se preciso for, numa luta de reivindi- 
cações justas (...) em um momento de reflexão sabereis medir quanta dose de bem-estar trareis para a coletividade estivadora de Santos, quebrando de vez a Bastilha de todos os preconceitos, quer de religião, quer de cor política, quer de nacionalidade, que tanto nos humilha e envergonha. Unamo-nos, formemos um só bloco, unido e coeso, não esquecendo que é da união que nasce a força e que uma casa subdividida não pode resistir, e ao invés de empenharmo-nos numa luta de interclasse, inglória (...) 1- Procurarei por todos os meios e recursos necessários à unificação de todos os associados dentro do mesmo estímulo: trabalho e união para a grandeza de nossa classe; 2- Procurarei ser a todos, dentro da ordem e justiça, isento de paixões e partidarismos.

\section{Características do trabalho da estiva}

O trabalho da estiva consta de estivagem e desestivagem, ou seja, a arrumação e a retirada das mercadorias exclusivamente no convés e nos porões do navio. Na terra, a função é do doqueiro, que caracteriza o antagonismo porto versus navio. $\mathrm{O}$ trabalho da estiva varia de acordo com a mercadoria a ser transportada, o que acentua, ainda mais, as características do trabalho e da mão-de-obra.

A carga é avaliada de acordo com o acondicionamento e o transporte requerido. O trabalho é diversificado e definido como nobre e não-nobre. No primeiro caso, utiliza-se a maquinaria. No segundo, depende-se exclusivamente do esforço físico, que é onde se encontram os produtos tóxicos e a granel (hoje já está sendo usada tecnologia específica, que elimina o esforço físico). O tipo de carga define a remuneração.

Antes da Lei de Modernização dos Portos (a partir de 1993, principalmente), os cálculos relativos à remuneração da estiva eram feitos pela hoje extinta Sunamam - Superintendência Nacional da Marinha Mercante, autarquia vinculada ao Ministério dos Transportes.

A estiva, na categoria de sindicato avulso, tinha seu salário administrado pelo Estado e percebido por meio da entidade estivadora, a agência intermediária que representa, no porto, os armadores. Os problemas relativos à remuneração e ao trabalho em geral, eram resolvidos no Ministério do Trabalho. Em situação de conflito de trabalho da estiva, quem interferia era o conselho, que era um órgão fiscalizador das delegacias de trabalho, presidido por um elemento da Marinha, o capitão dos portos, além de representantes da capital e um representante dos estivadores. 
Ao conselho competia prever e fixar horário de trabalho, determinar o número de homens necessários na composição de cada terno. ${ }^{1}$ Além disso, deveria prover e fixar o número de estivadores de acordo com o movimento do porto. Poderia também promover a rescisão de matrículas de trabalhadores que há mais de dois anos não exerciam a profissão.

O capitão dos portos tinha ainda a função de efetuar as matrículas dos estivadores no limite fixado pela Delegacia do Trabalho Marítimo.

\section{O controle do mercado de trabalho pelo sindicato}

As exigências para atuar na categoria de operário estivador começavam com a sindicalização do trabalhador que deveria, depois de matriculado na Capitania dos Portos, efetivá-la junto ao SES, uma vez que a CLT dá preferência ao trabalhador sindicalizado. Tal fato, como ressalta Sarti (1988), é uma legitimação do privilégio concedido aos membros do SES, além de reconhecer a coexistência de dois setores de uma mesma categoria da classe operária, setores (como enfatiza a autora) hierarquizados em função da situação de sindicalizado ou não. É relevante mostrar que, até a implantação do Órgão Gestor de Mão-de-obra (Ogmo), criado pela Lei de Modernização dos Portos, a matrícula dos estivadores no trabalho da estiva era controlada pelo SES.

Esse controle provocou, no passado, conflitos entre o capitão dos portos e a direção sindical. O SES, impedindo a matrícula de novos estivadores, e o capitão dos portos determinando-as. O fechamento da categoria era uma das estratégias políticas do SES que, com isso, garantia maior remuneração aos sindicalizados, ao mesmo tempo que assegurava maior poder político. Isso significa dizer que, com menor número de trabalhadores na estiva, e selecionados por ele, o poder do SES junto aos operadores portuários tornou-se maior, uma vez que tinha condições de parar o porto com sucesso.

Ao analisar essa questão, Sarti (1988) menciona que a disputa do poder entre o capitão dos portos e a direção do SES foi, no decorrer dos anos, favorecendo o SES. Em 1946, o capitão dos portos ameaçou intervir no sindicato, conseguindo efetuar 2.413 matrículas. Em 1952, a direção do SES se negou a acatar a decisão do capitão dos portos, rejeitando a matrícula de 587 trabalhadores. A partir daí, o SES passou a exercer o controle total do trabalho da estiva do porto de Santos.

\footnotetext{
1 Terno significa o grupo de trabalhadores necessários para realizar o trabalho de carga e descarga em um navio específico.
} 
O nepotismo, como ideologia, esteve presente no SES desde sua origem, pois sempre prevaleceu o privilégio de sindicalização para filhos, parentes e amigos dos membros sindicalizados. As matrículas na estiva, e a sindicalização de novos membros, seguiam o critério de reserva de mercado para os familiares e amigos próximos. A mudança, em parte, dessa política nepotista, se deu por meio de um decreto-lei de 1946, que garantia as diretrizes da reserva de mercado familiar, mas ao mesmo tempo, limitava-o, restringindo a $50 \%$ a proporção de vagas para filhos de sócios.

A tendência do fechamento do SES em torno de uma família estivadora sofreu, em 1962 (Sarti, 1988), mais uma intervenção do governo. O Ministério do Trabalho regulamentou o processo de sindicalização, estipulando a condição preferencial para os que já estavam trabalhando há mais tempo, a título precário, e que possuíam maiores encargos familiares, determinando também o número de horas de trabalho que passou a ser de 260 horas mensais.

A crise dos "bagrinhos", surgida em 1961, que ocasionou uma greve no porto de Santos, retrata, segundo Sarti (1988), um acontecimento político na sua inspiração, mas que, objetivamente, girava em torno do fechamento do SES à sindicalização de trabalhadores não pertencentes à "família estivadora santista".

Para entender melhor a "crise", é importante conhecer o significado do próprio termo "bagrinho", que é dado aos trabalhadores da estiva não-sindicalizados. Seu trabalho é, geralmente, constituído por atividades consideradas não-nobres, com remuneração menor. Essa situação facilitava o desvirtuamento das relações de trabalho na estiva, com a figura da sublocação, em que o trabalhador sindicalizado assume sua jornada de trabalho, mas não a realiza, passando-a para o não-sindicalizado. Nessa transação, o estivador sindicalizado fica com a maior parte da remuneração. Ele repassa o trabalho, mas não a remuneração devida ao mesmo.

Surgiu, assim, um processo distorcido de relação de trabalho na estiva e, com ele, algo antes nunca visto no processo organizado de trabalho: a exploração do trabalhador pelo próprio trabalhador. O sindicato negava (e ainda nega) sua existência, mas é voz corrente que o comércio ilegal ainda persiste na estiva.

A crise dos "bagrinhos" concentrou as atenções do país e das autoridades sobre o porto de Santos, envolvendo as Forças Armadas, o Poder Legislativo, o Poder Judiciário e o Poder Executivo, acarretando ações diretas dos ministros e do próprio presidente da República.

Em 1961, o capitão dos portos do porto de Santos fixou em 1.004 o número de vagas para estivadores. O SES não aceitou e entrou com protesto no Departamento de Transportes Marítimos (DTN), alegando a ilegalidade do levantamento feito pelo capitão dos portos. 
Como a estiva não pôde se manifestar na Justiça por erros estratégicos da diretoria do SES, o DTN expediu 275 matrículas de estivadores, determinando sua imediata sindicalização. O SES, entretanto, se negou a sindicalizálos. Os "bagrinhos" apelaram ao Ministério do Trabalho por meio da Delegacia Regional do Trabalho e a sindicalização dos trabalhadores foi confirmada.

O Ministério do Trabalho baixa, então, portaria que determina que seja de 260 o mínimo de horas necessárias a cada estivador, e que a mão-de-obra do porto deveria ser aumentada apenas quando o trabalhador superasse essas horas. Nesse momento, entrou em cena Herbert Levy, deputado federal pela UDN, que assume a defesa dos estivadores não-sindicalizados, interpelando o ministro do Trabalho.

A questão do congestionamento do porto de Santos, então em discussão, foi levantada por ele, que a entendia ocasionada pela falta de operários estivadores. O agravamento da crise dos "bagrinhos" envolve a Marinha e o Exército, este dividido: enquanto o ministro da Marinha enviou um torpedeiro da Marinha de Guerra com 900 fuzileiros navais para proteger o SES, o comandante do II Exército, em São Paulo, mandou tropas a Santos para ocupar a cidade.

Como a ordem do Poder Judiciário para a sindicalização dos trabalhadores não foi cumprida, a intervenção no SES foi efetuada. Depois de uma greve iniciada em 5 de julho de 1963 e terminada três dias depois, 275 matriculados não foram admitidos no SES. Em dezembro, 200 matriculados foram admitidos no sindicato. Nesse ínterim, o Tribunal Federal de Recursos sustou os efeitos do mandado de segurança concedido aos matriculados, por ato do subprocurador-geral da República, que solicitou suspensão da segurança concedida pelo próprio TRF.

Sua alegação para a suspensão foi que, ao Ministério do Trabalho competia não só assegurar trabalho a todos mas garantir aos que trabalham remuneração condigna. Com essa argumentação, deixava claro sua posição política a favor do SES e de sua política corporativista e nepotista. Esse parecer, entretanto, só foi julgado em março de 1964, quando o SES foi definitivamente derrotado.

A crise do "bagrinho", eclodida em 1961 e terminada após o golpe militar de 1964, explicita as conseqüências da política corporativista e do nepotismo predominante no SES que, no emaranhado do jogo político, fragilizou-se. Com isso, a oportunidade de reorientar a política sindical de maneira mais autêntica e mais adequada ao momento político do país foi perdida.

As reivindicações da estiva do porto de Santos, entre 1955 e 1964 são importantes para compreender a ideologia sindical e suas ações. Sarti (1988) apresenta as reivindicações de caráter econômico, que implicam em vantagens sobre salário, bem como as de tipo técnico e de organização do trabalho. As reivindicações podem ser visualizadas, por ano, nos quadros 1 e 2 . 


\begin{tabular}{|c|}
\hline $\begin{array}{l}\text { Quadro } 1 \\
\text { Reivindicações de caráter econômico }\end{array}$ \\
\hline $1955-58$ \\
\hline $\begin{array}{l}\text { Taxa de insalubridade - determina 35\% de taxa adicional ao salário para as mercadorias que necessitem } \\
\text { de material de proteção (Resolução } \mathrm{n}^{0} \text { 1.195, Boletim, } \mathrm{n}^{-0} \text { 175) }\end{array}$ \\
\hline $\begin{array}{l}\text { Taxa de periculosidade - estipula aumento de } 30 \% \text { para substâncias inflamáveis, entendidas como "toda } \\
\text { substância que, sendo combustível, inflama-se ao mais ligeiro contato de uma chama" (Decreto n⿳0 2.573, } \\
\text { de } 23 \text { de setembro de 1955) }\end{array}$ \\
\hline Majoração da carga de cimento nacional como carga geral \\
\hline Metro cúbico - regulamentação do pagamento por produção considerando a "cubagem" da mercadoria \\
\hline $1959-61$ \\
\hline $\begin{array}{l}\text { Divisão da produção da embarcação auxiliar por seis homens, pagando-se os dois portalós como reforço, } 0 \\
\text { que corresponde a } 33 \% \text { de aumento }\end{array}$ \\
\hline $\begin{array}{l}\text { Pagamento de 30\% como adicional de periculosidade nas operações do largo da ilha de Barnabé e do cais do } \\
\text { Sabó }\end{array}$ \\
\hline $\begin{array}{l}\text { Aplicação de } 20 \% \text { nas taxas e salários no período destinado às refeições, das } 11 \mathrm{~h} \text { às } 12 \mathrm{~h} 30 \mathrm{~min} \text {, das } 18 \mathrm{~h} \text { às } 19 \mathrm{~h} \text {, } \\
\text { e das } 22 \mathrm{~h} \text { às } 23 \mathrm{~h}\end{array}$ \\
\hline Pagamento integral do repouso semanal remunerado, ou seja, $1 / 6$ nos horários acima citados \\
\hline Pagamento do repouso semanal remunerado nos dias feriados \\
\hline Pagamento das majorações nos suplementos das refeições \\
\hline $\begin{array}{l}\text { Pagamento integral do período de prorrogação, de } 2 \mathrm{~h} \text { às } 4 \mathrm{~h} \text { da manhã, mesmo sendo o terno dispensado no } \\
\text { início do período }\end{array}$ \\
\hline Pagamento por produção aos guincheiros que sejam engajados para abertura e fechamento dos porões \\
\hline Equiparação da taxa do açúcar com corte na boca da escotilha à taxa do açúcar acondicionado em sacos \\
\hline $\begin{array}{l}\text { Pagamento como taxa de carga geral às seguintes mercadorias: mamona, babaçu, oiticica, batatas, caroço de } \\
\text { algodão, tucum e cacau, que anteriormente estavam classificadas como cereais. Essa transformação corres- } \\
\text { ponde a } 65 \% \text { de aumento em relação à produção dessas mercadorias }\end{array}$ \\
\hline $\begin{array}{l}\text { Pagamento integral ao contramestre-geral que seja engajado às } 13 \mathrm{~h} \text {, quando já haja um terno em operação } \\
\text { desde às } 7 \mathrm{~h}\end{array}$ \\
\hline Cotas de contramestre geral-pelos períodos de maior produção \\
\hline $\begin{array}{l}\text { Pagamento do adicional de } 30 \% \text { do período de serviço quando sofre interrupção por motivo de chuva, inclu- } \\
\text { sive nas horas paradas }\end{array}$ \\
\hline Pagamento como reforço aos guincheiros tirados após as horas regulamentadas de engajamento do terno \\
\hline Soma as horas paradas à produção \\
\hline Pagamento das horas paradas com o adicional de insalubridade, quando se opera com carga majorada \\
\hline Salário do enxofre e superfosfato majorado em 100\%, horas paradas inclusive \\
\hline
\end{tabular}


Salário de Couro Verde aberto no porão majorado em $50 \%$

Manutenção da classificação do adubo como carga geral, cujo ato da CMM reduzia o salário do estivador em $65 \%$ quando no manuseio do adubo ensacado

Taxa de insalubridade de 35\% referente ao salitre do Chile

Taxa-sábado: adicional de $25 \%$ para o segundo turno de trabalho aos sábados

Equiparação da taxa de tonelagem com a cubagem: até aqui as taxas de cubagem implicavam remuneração $40 \%$ inferior às de tonelagem (Resolução $\mathrm{n}^{0}$ 2.132, Boletim $\mathrm{n}^{0} 320$ da CMM, de 17 de novembro de 1961)

$1962-64$

Questões dos petroleiros - reconhecido o direito dos estivadores de Santos de trabalhar nos navios da frota nacional de petroleiros quando estes não contarem com pessoal especializado a bordo

Pagamento de décimo terceiro salário

Reivindicações de tipo técnico e de organização do trabalho

\section{Quadro 2}

Reivindicações do tipo técnico e organização do trabalho

$1955-58$

Estabelecimento do sistema de "Roda Grande" - distribuição eqüitativa do trabalho

Rodízio de fiscais e contramestres-gerais (Leis $\mathrm{n}^{\underline{0 S}} 1.872$ e 1.856)

Condução para transportar os trabalhadores que se destinam ao serviço no lado do mar e do navio, particularmente nas lanchas de banana

Obrigatoriedade de duas horas para abrir e fechar os porões dos navios carregados com trigo e sal, desde que usem aparelhos automáticos

Reforço para o trabalho de carvão quando distante

Pagamento envelopado e individual

Cavalete para bailéus

Oferta de gigo para embarque de banana, pelo SES, cobrando aluguel das entidades estivadoras

$1959-61$

Uso de tabuleiros de aço ou de madeira

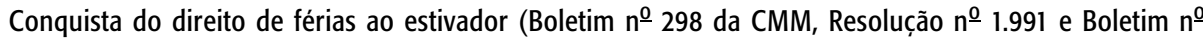
304, Resolução no 2.031, Diário Oficial, 20 out. 1960 e 23 jan. 1961, respectivamente), sendo designados $7 \%$ para cobertura das férias, assim discriminados: 5,56\% para 0 estivador e 1,44\% destinados à administração e à cobertura dos compromissos sociais do empregador (como lapetec, SSR e LBA)

Fornecimento de água potável ao estivador quando em serviço (Boletim no 298 da CMM, Diário Oficial, 20 out. 1960)

Colocação de um estivador, denominado "aguadeiro", para fornecimento de água potável ao estivador em serviço

Pagamento de todos os serviços de estiva por meio de divisão de período

Reintegração do sindicato estivador à “Caixa de Acidentes" (Decreto nº 49.383, de 30 de novembro de 1960). 


\section{Distribuição do trabalho no passado e no presente: sindicato versus Ogmo}

A partir de 1946, o Sindicato dos Estivadores passou a ter controle total na distribuição do trabalho no porto de Santos. Nesse contexto, é importante verificar as características do trabalho da estiva, que depende tanto da chegada dos navios quanto do tipo de carga que transportam. Quando os navios atracam, a carga é ofertada em cada ponto do cais, onde os trabalhadores são escolhidos para a jornada do dia. Esses pontos são denominados paredes.

A distribuição do trabalho seguia o ritual do fazer fé, ou seja, levantar a carteira sindical no dia do câmbio (Sarti, 1988; Tavares, 2001). ${ }^{2}$ O modelo de Roda Grande usado pelo Sindicato dos Estivadores de Santos estabelecia que o estivador teria direito de estar dois dias por semana (denominado câmbio) em pontos de distribuição, para participar da luta pelo direito ao trabalho. Esses dois dias eram registrados em seu cartão sindical.

Diariamente, 20 equipes, com 300 trabalhadores cada uma, disputavam, de acordo com seu câmbio, a formação dos ternos de trabalhadores.

Os critérios para a escolha dos ternos, além da exigência de estar no câmbio, segundo o próprio SES, eram idade, tempo de sindicalização e condições físicas.

A denominação "Roda Grande" tem sua origem no movimento circular inverso, do rodízio dos estivadores e dos contramestres ou coordenadores de equipes. É importante ressaltar que o SES tinha 60 diretores que constituíam o corpo de contramestres que, apesar de serem avulsos, tinham o trabalho diário garantido, não participando do "câmbio".

A modernização portuária brasileira, que ocorreu com a Lei $n^{0}$ 8.630/ 93 e a Lei no ${ }^{9} .719 / 98$, cria o Órgão Gestor da Mão-de-Obra (Ogmo), que regulamenta a forma de gestão do trabalho portuário avulso. No Capítulo IV, art. 18 (Gempo - Grupo do Executivo para a Modernização dos Portos, 1999), fica definido que em cada porto organizado os operadores portuários deverão constituir um órgão de gestão da mão-de-obra do trabalhador portuário com as seguintes finalidades:

、 administrar o fornecimento da mão-de-obra do trabalhador portuário e do trabalhador portuário avulso;

\footnotetext{
${ }^{2}$ Dia do câmbio - dia em que o trabalhador tinha direito de apresentar-se como candidato ao trabalho no porto.
} 
v manter, com exclusividade, o cadastro do trabalhador portuário e o registro do trabalhador;

\ promover o treinamento e a habilitação profissional do trabalhador portuário, inscrevendo-o no cadastro;

v selecionar e registrar o trabalhador portuário avulso;

、 estabelecer o número de vagas, a forma e a periodicidade para acesso ao registro do trabalhador portuário avulso;

v expedir os documentos de identificação do trabalhador portuário;

\ arrecadar e repassar aos respectivos beneficiários os valores devidos pelos operadores portuários, relativos à remuneração do trabalhador portuário avulso e aos correspondentes encargos fiscais sociais e previdenciários.

Essa mesma lei estabelece que, somente em casos de acordo coletivo de trabalho no porto, entre trabalhadores e quem contrata seus serviços, não haverá intervenção do Ogmo nas relações capital-trabalho. É nesse sentido que a implantação do Ogmo como um dos elementos centrais no processo de modernização dos portos do país tem ocasionado conflitos e lutas com os sindicatos dos estivadores. Tais conflitos ocorrem em função da mudança introduzida no papel dos sindicatos na alocação da mão-de-obra portuária, tanto que, em 1998, o Tribunal Regional do Trabalho, na Bahia, estabelece que os sindicatos dos portuários do estado não terão direito de escalar trabalhadores e nem de determinar o número de homens por turno. A decisão ocasionou a denominada operação-padrão para reduzir a velocidade na movimentação das cargas nos navios.

Diante dessa situação, três federações nacionais de trabalhadores dos portos ingressaram no Tribunal Superior do Trabalho, pedindo efeito suspensivo da decisão. $O$ receio dos trabalhadores era de que, ao se estabelecer, na Bahia, novo modelo de gestão da mão-de-obra, com o Ogmo, a norma seria estendida a todos os portos nacionais. Conforme declaração do presidente da Federação Nacional dos Portuários, a escalação dos trabalhadores pelos sindicatos era uma tradição de mais de 100 anos. E não poderia ser alterada. Ainda, segundo ele, os sindicatos saberiam definir a competência do trabalhador para a função e garantir sua escalação sem discriminação, o que ocorria com o Ogmo, pois este não possui regras e nem critérios para a escalação dos portuários para o trabalho. 
É importante ressaltar que o então presidente da Federação Nacional dos Portuários era, também, presidente do Sindicato dos Estivadores do Porto de Santos.

Em novembro de 1999, representações sindicais de portuários iniciaram ação junto a deputados da Câmara Federal, a fim de excluir ou modificar os itens referentes aos portos, do projeto de lei que criava a Agência Nacional dos Transportes. Naquele momento, a preocupação dos sindicatos era com a privatização das autoridades portuárias. Mais uma vez, o porta-voz dos portuários foi o presidente da Federação Nacional dos Portuários, que expressava o temor de demissões em massa nos portos.

Os estivadores do porto de Santos já haviam aprovado, em 1997, redução de equipes de trabalho e aumento de produtividade, além da equiparação gradativa do custo dos estivadores à da mão-de-obra da Cosipa. Na época, o Sindicado dos Estivadores previu que, de acordo com o contrato firmado com a Cosipa, haveria uma redução de $75 \%$ do ganho dos trabalhadores da categoria nesse terminal. É importante ressaltar que tal terminal representava, na época, $40 \%$ do mercado de trabalho dos estivadores no porto de Santos, e que a diretoria do SES defendia, naquele momento, a proposta de redução das equipes e da própria remuneração, para garantir os postos de trabalho na Cosipa.

O Ogmo começou a operar em Santos no final de 1995, processando a folha de pagamento dos trabalhadores avulsos que continuavam sendo escalados pelos sindicatos. Em 1998, o Congresso Nacional transfere para o Ogmo a tarefa de escalar os avulsos. No porto de Santos, das sete categorias de avulsos, duas se recusaram a aceitar essa transferência: a dos estivadores e dos trabalhadores de bloco. Os estivadores não aceitaram a transferência da competência e, mesmo comparecendo aos postos de escala, não aceitaram o serviço. A paralisação durou três dias, ocasionando a parada da movimentação do cais, e encerrou-se no dia 26 de março de 2001, sem uma solução definitiva. Houve, então, por parte do Ministério do Trabalho, exigência para que o sindicato cumprisse a sentença judicial. Em 27 de março, data para entrada em vigor da escalação dos estivadores sob o comando do Ogmo, eles voltaram a comparecer aos portos de escala, sem aceitar os serviços.

O Tribunal Regional do Trabalho de São Paulo concedeu, então, liminar determinando a volta dos estivadores ao trabalho no dia 30 de março, sob pena do sindicato pagar uma multa diária de $\mathrm{R} \$ 50$ mil. Depois de 14 dias de greve no porto de Santos, acordo firmado em 11 de abril de 2001, entre o Ogmo e os sindicatos dos estivadores e dos trabalhadores de bloco, com o aval do Ministério Público, concretizou a escala da estiva e do bloco. Tal acordo homologou a implantação, pelo Ogmo, de uma nova metodologia de ges- 
tão do trabalho portuário, estabelecendo a manutenção das 20 turmas, compostas por 300 homens em média cada uma, todos com escalação em rodízio numérico.

Nesse sistema permanecem os 480 mestres, substituídos a cada 80 dias, além dos 100 câmbios livres, e 238 monotécnicos, todos distribuídos em rodízio numérico.

Permanecem, ainda, os 80 monitores de parede (antigos diretores e fiscais), na proporção de quatro por turma, também substituídos a cada 80 dias.

A novidade é o rodízio entre os 80 monitores, antigos diretores e fiscais, substituídos a cada 80 dias, o que não existia anteriormente.

Segundo avaliação do gerente de Recursos Humanos do Ogmo, essa nova metodologia de escalação possibilita uma forma mais eqüitativa na distribuição dos serviços, tendo a escalação em sistema de rodízio proporcionado oportunidades iguais a todos os trabalhadores e, conseqüentemente, uma distribuição de remuneração mais equilibrada e justa.

Com base nas listas das 20 turmas, fornecidas pelo Sindicato dos Estivadores, quando da transferência da escala, o Ogmo divulga a relação de estivadores para exercerem a função. Até 5 de junho de 2001, os trabalhadores convocados deveriam fazer a opção junto ao órgão, caso desejassem assumir o cargo, bem como passar por exame médico e receber treinamento para uso correto do equipamento de proteção individual (EPI). Caso não o fizessem, a ausência seria interpretada como desistência, e a entidade convocaria o número seguinte.

O Ogmo implementou, também, na distribuição dos trabalhadores, o sistema integrado escalação/pagamento - Siep, que prevê, após o término da escalação, a emissão online da planilha de escala ao setor de pagamentos, com o nome dos estivadores engajados, disponibilizando o confronto das informações entre o setor de pagamento e os operadores portuários, assim como a emissão de cartões personalizados para acesso dos trabalhadores escalados ao cais e aos navios.

Com essa transferência, o órgão concluiu o processo de escalação e assumiu, em sua totalidade, a distribuição dos 11.044 trabalhadores avulsos em Santos, ou seja, assumiu a gestão da mão-de-obra portuária e estabeleceu uma nova dinâmica no porto de Santos, dando uma nova forma ao porto organizado.

\section{Considerações finais}

Este artigo constitui uma primeira aproximação temática, visando o desenvolvimento de pesquisa mais ampla acerca da complexidade das relações de tra- 
balho existentes entre o Sindicato dos Estivadores do Porto de Santos e o próprio porto.

As reivindicações da estiva, no passado do porto (1920-70), quando confrontadas com as reivindicações do presente (2000-05), não apenas demonstram, mas são indicadoras dos compromissos e das ideologias divergentes.

Dos anos 1920 a 1950, o porto tinha um maior compromisso com o anarquismo sindical, tendo seus pressupostos ideológicos traçado diretrizes de ação comprometidas com um ideal universal de condições de vida do trabalhador.

Na "era comunista" do porto, a proposta de uma "luta universal" pela emancipação do trabalhador se apresentou de forma diferenciada, mas continua presente e viva na vida do Sindicato dos Estivadores de Santos. Entretanto, apesar do compromisso ideológico sempre presente, permaneceu, no porto, o predomínio do corporativismo e do nepotismo, em suas várias estruturas e nuances dinâmicas.

As reivindicações, todavia, tanto de caráter econômico quanto de tipo técnico e de organização do trabalho, representaram, na época, reais respostas aos problemas e às demandas dos trabalhadores da estiva. E ainda têm importância na análise do porto, de suas relações de trabalho e do Sindicato dos Estivadores como um dos atores sociais no processo de modernização portuária.

O presente do porto não é diferente. Existe ainda um forte compromisso com o corporativismo e com o status quo. É um processo que exige não apenas decisões, mas a mudança de valores e práticas institucionais. Os sindicatos possuíam o controle do porto, privilegiando apenas seus interesses corporativos. Mudar esse quadro exigia um projeto político que privilegiasse os interesses nacionais e não apenas os das categorias portuárias.

O Sindicato dos Estivadores de Santos ignorou, ou negou reconhecer as grandes mudanças que vinham ocorrendo no país e no mundo globalizado, que exigiam repensar sua ação política, e da classe trabalhadora que representava e ainda representa. Por isso, as mudanças ocorreram lentamente, colocando à margem os trabalhadores e seus interesses, pois o país necessitava modernizar o porto e sua gestão. Sem dialogar com os novos atores portuários, apenas sofreram as mudanças tecnológicas que, rápidas, afetaram a vida dos trabalhadores da estiva e dos portuários em geral, pois elas não poderiam ser interrompidas. Entretanto, refletir sobre elas, e procurar caminhos e respostas que anulem seus efeitos de exclusão econômica e social, devem ser questões prioritárias de uma ação sindical responsável. O Sindicato dos Estivadores de Santos não pode ignorar sua responsabilidade como ator integrante do processo de modernização do porto de Santos e da economia brasileira. 


\section{Referências bibliográficas}

AGUIAR, M. A. F. O Sindicato dos Estivadores na contramão do processo de modernização do porto de Santos. In: JUNQUEIRA, Luciano A. Prates (Org.). Desafios da modernização portuária. São Paulo: Aduaneiras, 2002.

ALEXANDRINO, C. S. M. Sombras sobre Santos. Santos: Prefeitura Municipal de Santos, 1988.

AMADO, J. Subterrâneos da liberdade II — a agonia da noite. São Paulo: Martins, 1964.

ANZIEU, D. O grupo e o inconsciente: o imaginário grupal. São Paulo: Casa do Psicólogo, 1993.

ASSESSORIA SINDICAL. A modernização portuária brasileira. s.d.

AZEVEDO, R. A resistência anarquista: uma questão de identidade (1927-1937). 1996. Dissertação (Mestrado em História) — Faculdade de Filosofia, Letras e Ciências Humanas, USP, São Paulo.

BECK, U. O que é globalização. São Paulo: Paz e Terra, 1999.

. Modernização reflexiva. São Paulo: Universidade Estadual Paulista, 1997.

BRASIL menos caro. Folha de S. Paulo, 19 set. 1997. Folha Opinião.

CARONE, E. Brasil: anos de crise (1930-1945 ). São Paulo: Ática, 1991.

CASTANHÊDE, E. Projeto que cria Agência Nacional dos Transportes deve ir hoje ao Congresso. Folha de S. Paulo. 13 ago. 1999. Caderno Dinheiro.

CASTELLS, M. A sociedade em rede. São Paulo: Paz e Terra, 1999.

DIAS, E. Histórias das lutas sociais no Brasil. São Paulo: Edaglit, 1962.

DISPUTA por escalação leva a impasse. Folha de S. Paulo, 31 mar. 2001.

FREDDO, A. C. O Brasil hoje: uma visão sociológica. RAP, Rio de Janeiro: FGV, v. 32, n. 3, p. 234-247, maio/jun. 1998.

- Modernização portuária, poder e violência. In: JUNQUEIRA, Luciano A. Prates

(Org.). Desafios da modernização portuária. São Paulo: Aduaneiras, 2002. p. 33-53.

GEMPO (GRUPO EXECUTIVO PARA MODERNIZAÇÃO DOS PORTOS). Legislação portuária, out. 1999.

GENTILI, P. (Org.). Globalização excludente. Petrópolis: Vozes, 1999. 
GIDDENS, A. Para além da esquerda e da direita. São Paulo: Universidade Estadual Paulista, 1996.

GITAHY, M. L. C. Ventos do mar: trabalhadores do porto, movimento operário e cultura urbana. São Paulo: Universidade Estadual Paulista, 1992.

GONÇALVES, A. Lutas e sonhos: cultura política e hegemonia progressista em Santos (1945-1962). São Paulo: Unesp, 1995.

LOPES, M. O porto, porta, poros. In: BRESCIANI, S. (Org.). Imagens da cidade: séculos XIX e XX. São Paulo: Marco Zero, 1994.

MANTELLI, W. Portos, pouco a comemorar. Folha de S. Paulo, 31 mar. 1998. Caderno Dinheiro.

MÃO-DE-OBRA pesa até 83\% nos custos. Folha de S. Paulo, 13 jun. 1998. Caderno Dinheiro.

MARAM, Sheldon L. Anarquistas, imigrantes e o movimento operário brasileiro, 1890-1920. Rio de Janeiro: Paz e Terra, 1979.

MARTINS, C. (Coord.). Memória do movimento sindical de Santos (1930-1964). São Paulo: Fundação Arquivo e Memória de Santos, 1997.

MATTOS, A. Brasil cresce e já vive escassez de portos. Folha de S. Paulo, 17 abr. 2001. Caderno Dinheiro.

MEYER, H. City and port. Transformation of port cities. Rotterdam: International Books, 1999.

MINISTRO reclama que custo dos terminais privados caiu pouco. Folha de S. Paulo, Brasília, 2 set. 1999.

OGMO. Nosso porto. Informativo Bimestral, Santos, n. 2, 2001.

RIFKIN, Jeremy. O fim dos empregos: o contínuo crescimento do desemprego em todo o mundo. São Paulo: M. Books do Brasil, 2004. Edição Histórica - 10 anos.

ROLLI, C. Força faz churrasco de protesto. Folha de S. Paulo, 13 fev. 2001. Caderno Dinheiro.

SANTIL, J. M. Queda-de-braço no porto. Sindicato dos Estivadores luta para sobreviver aos efeitos da modernização no porto de Santos. São Paulo: Universidade de São Paulo, 1998.

SARTI, I. O porto vermelho: os estivadores santistas no sindicato e na política. Rio de Janeiro: Paz e Terra, 1988.

SCHOEPS, W.; DELAZARO, W. (Coords.). Influência econômica do porto de Santos. São Paulo: Agir, 1980.

SILVA, Fernando Teixeira da. Operários sem patrões: os trabalhadores da cidade de Santos no entreguerras. São Paulo: Unicamp, 2003. 
SILVA, Gerardo; COCCO, Giuseppe (Orgs.). Cidade e portos: os espaços da globalização. Rio de Janeiro: DP\&A, 1999. (Coleção Espaços do Desenvolvimento.)

SIQUEIRA, F. Estivadores aprovam salário menor. Folha de S. Paulo, 31 jul. 1997. Caderno Dinheiro.

- Operação padrão reduz ritmo de trabalho em todos os portos. Folha de S. Paulo, 20 maio 1998. Caderno Dinheiro.

- Portuários se movimentam para mudar projeto de lei. Folha de S. Paulo, 3 nov. 1999. Caderno Dinheiro, 1.

Boicote em porto termina antes de começar. Folha de S. Paulo, 17 jan. 2001a. Caderno Dinheiro.

—. Estivadores paralisam o porto de Santos. Folha de S. Paulo, 30 jan. 2001b. Caderno Dinheiro.

—. Estivadores do porto de Santos armam boicote. Folha de S. Paulo, 13 fev. 2001c. Caderno Dinheiro.

- Estivadores encerram greve no porto de Santos. Folha de S. Paulo, 9 abr. 2001d. Caderno Dinheiro.

- Porto de Santos espera passar hoje pelo primeiro dia de atividades normais. Folha de S. Paulo, 12 abr. 2001e. Caderno Dinheiro.

TAVARES, Rodrigo R. Porto vermelho: a maré revolucionária (1930-1951). Inventário do Deops. Modelo VI. Comunistas. São Paulo: Imprensa Oficial do Estado, 2001.

ZOTTO, Tânia Christina. O Trabalho de estiva. Modernização x tradição: os desafios da tecnologia e da gestão no cats. São Paulo: LTr, 2002. 